\title{
Contributions to the study of the prevalence of oral breathing associated with angle class II/1 malocclusion
}

\author{
Contribuţii la studiul prevalenţei respiraţiei orale asociate \\ malocluziei clasa II/1 Angle
}

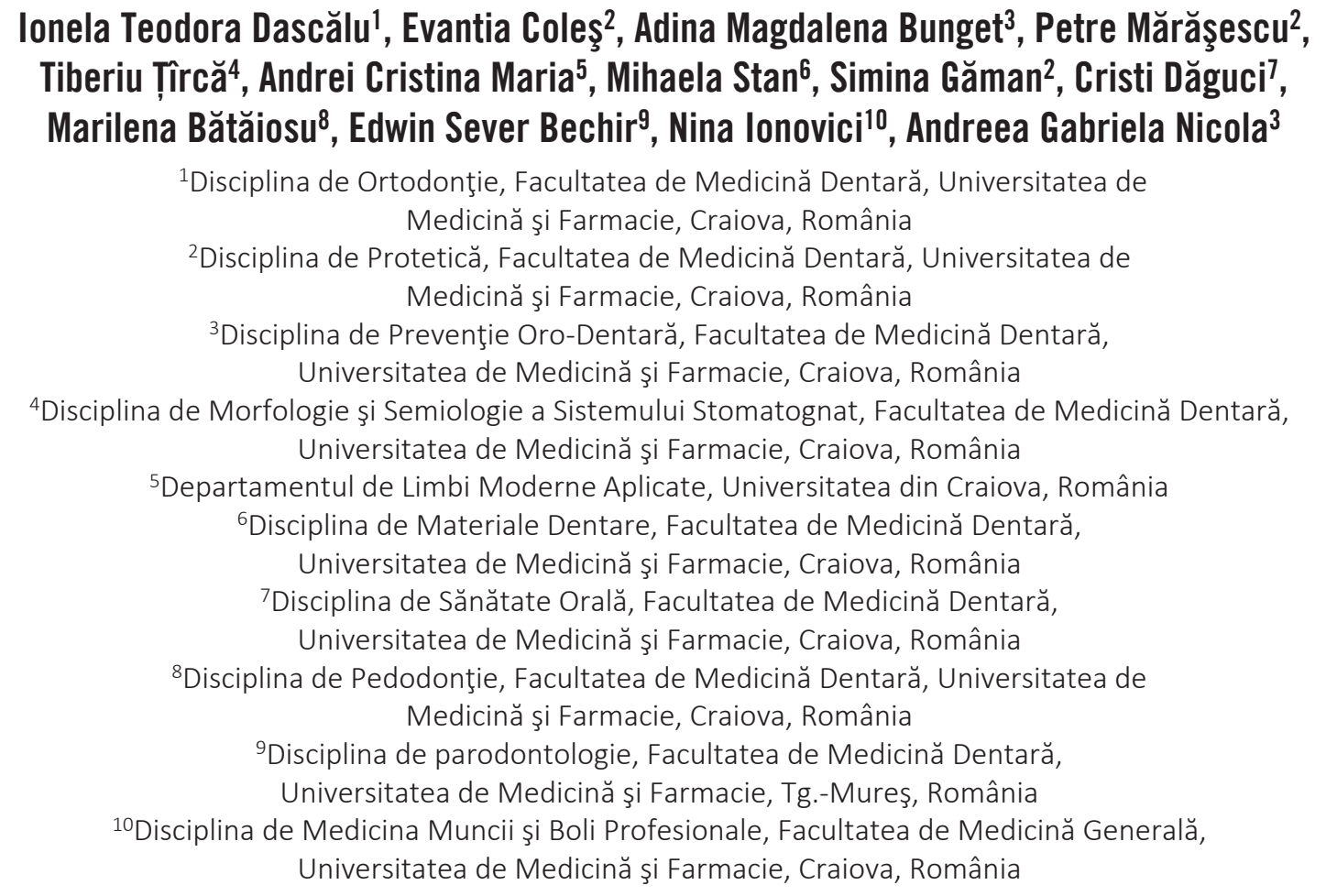

ABSTRACT
The obstruction of nasal passages determines the disturbance of the function of normal breathing, once the oral breathing is settled. The aim of the present paper is to bring a contribution to the analysis of the prevalence of oral breathing in the etiology of Angle Class II/1 malocclusion. 1,735 children aged 6 to 14/15 from the area of Craiova were part of the present study. The research has revealed a prevalence of $7,24 \%$ in the urban area and $6,47 \%$ in the rural one. The result is that, once the oral breathing is permanently settled, there may appear disorders in the cranio-facial development, sometimes leading to the appearance of Angle Class II/1 malocclusion.

Keywords: oral breathing, Angle Class II/1 malocclusion, early prevention

\section{REZUMAT}

Obstrucţia căilor nazale determină perturbarea funcţiei respiratorii normale cu instalarea unei respiraţii orale. Scopul studiului este de a contribui la analiza prevalenţei respiraţiei orale în etiologia malocluziei clasa II/1 Angle. Studiul s-a desfăşurat pe 1.735 de copii cu vârste cuprinse între 6 şi 14/15 ani din arealul Craiovei. În mediul urban, am găsit o prevalenţă de $7,24 \%$, iar în mediul rural de $6,47 \%$. Studiul nostru atrage atenţia asupra faptului că permanentizarea respiraţiei orale la copii determină tulburări de dezvoltare cranio-facială cu instalarea malocluziei de clasa a II/1-a Angle.

Cuvinte cheie: respiraţie orală, malocluzie clasa II/1 Angle, depistare precoce 


\section{INTRODUCERE}

Fratu (4) consideră că „respirația este o funcție biologică comună aparatului respirator şi dento-maxilar care asigură schimburile gazoase". În mod normal, inspirul se realizează prin cavitatea nazală, iar în anumite situații (efort fizic, obstrucție nazală) suplimentarea cantității necesare de aer se poate realiza prin respirație orală. Literatura de specialitate menționează că „,vegetațiile adenoide, amigdalitele cronice hipertrofice şi deviaţiile de sept sunt cauze determinante ale instalării în timp a respirației orale“. (5)

Permanentizarea respirației orale la copii reprezintă un element etiologic important în instalarea anomaliilor dento-maxilare şi, implicit, a malocluziilor clasa II/1 Angle.

Respiratorul oral prezintă fanta labială întredeschisă, buza superioară atonă şi scurtată. Limba nu mai ia contact cu bolta palatină şi deci nu-şi mai exercită presiunea fiziologică asupra pereților laterali ai acesteia.

Musculatura jugală fiind tensionată, determină compresia de maxilar şi distalizarea mandibulei, ceea ce permite poziționarea buzei inferioare în spațiul de inocluzie sagitală creat. Dinții frontali superiori ajung în vestibulo-poziţie şi, nefiind umectaţi de salivă, devin sensibili la apariția proceselor carioase prin lipsa efectului protector al salivei.

\section{SCOP}

Scopul studiului este de a contribui la analiza prevalenței respirației orale în etiologia malocluziei clasa II/1 Angle.

\section{MATERIAL ŞI METODĂ}

Studiul s-a desfăşurat în cadrul proiectelor: „Anomaliile dento-maxilare la şcolari“ şi „Studiul disfuncțiilor şi parafuncțiilor aparatului dento-maxilar (6-14/15 ani)“, desfăşurate în perioada 20142017. La studiu au participat 1.735 de copii cu vârste cuprinse între 6 şi 14 ani din arealul Craiovei. Pentru examinare am utilizat mănuşi de unică folosință. Am urmărit identificarea copiilor cu anomalii clasa II/1 Angle şi prevalența respirației orale în etiopatogenia acestei anomalii.

\section{REZULTATE ŞI DISCUŢII}

$\mathrm{Au}$ fost consultați şi luați în evidență copiii care prezentau semnele caracteristice unui respirator oral.
Din numărul total de 1.735 copii participanți la studiu, 870 au provenit din Craiova, iar 865 din mediul rural.

În cadrul proiectelor, în mediul urban am examinat 870 de copii, dintre care $427(49,08 \%)$ cu vârsta cuprinsă între 6 şi 10 ani şi $443(50,92 \%)$ cu vârsta cuprinsă între 11 şi 14 ani.

În mediul urban, din cei 870 de copii examinați, $146(16,78 \%)$ de copii au prezentat malocluzii clasa II/1 Angle, dintre care 63 (7,24\%) de copii cu malocluzii clasa II/1 Angle care au avut ca factor etiopatogenic respirația orală.

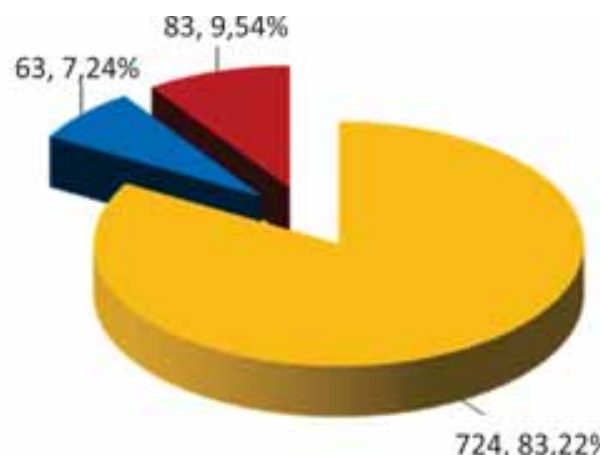

$\square$ Copii fără malocluzii II/1 Angle mediul urban

- Copii cu malocluzii II/1 Angle cu factor etiopatogenetic respirația orală - Copii cu malocluzii $11 / 1$ Angle cu alți factori etiopatogenetici

GRAFIC 1. Copii cu malocluzii clasa II/1 Angle din mediul urban

La grupa de vârstă 6-10 ani, 77 de copii (18,03\%) au prezentat malocluzii clasa II/1 Angle [45 fete $(10,54 \%)$ şi $32(7,49 \%)$ băieți].

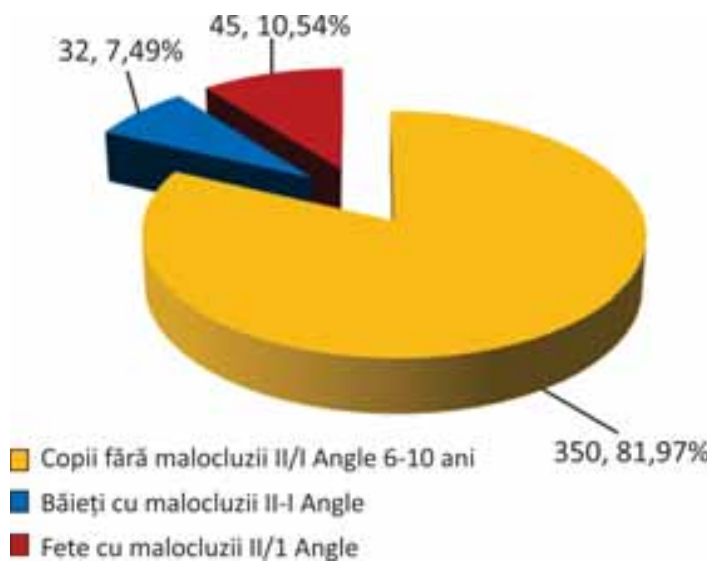

GRAFIC 2. Copii cu malocluzii clasa II/1 Angle din mediul urban la grupa de vârstă 6-10 ani

La grupa de vârstă 6-10 ani în mediul urban, respirația orală ca factor etiopatogenic în producerea acestei malocluzii a fost identificată la 33 copii $(7,73 \%)$ [18 (4,22\%) fete şi $15(3,51 \%)$ băieți]. 


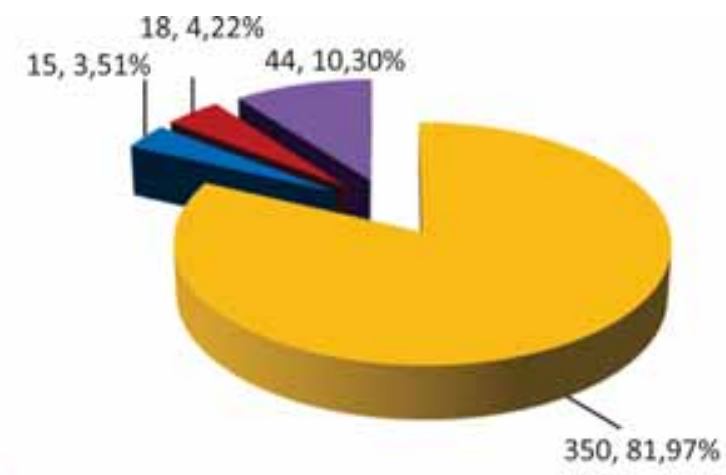

$\square$ Copii fără malocluzii il// Angle 6-10 ani

- Băieți cu malocluzii 11// Angle cu factor etiopatogenetic respirația oralà - Fete cu malocluyii II/I Angle cu factor etiopatogenetic respirația orală - Copii cu malocluzii II/I Angle cu alți factor etiopatogenetici

GRAFIC 3. Copii cu malocluzii clasa II/1 Angle determinate de respirația orală, cu vârste cuprinse între 6 şi 10 ani din mediul urban

La grupa de vârstă 11-14 ani, din cei 443 de copii examinați, $69(15,58 \%)$ au prezentat malocluzii clasa II/1 Angle [33 (7,45\%) fete şi $36(8,13 \%)$ băieți].

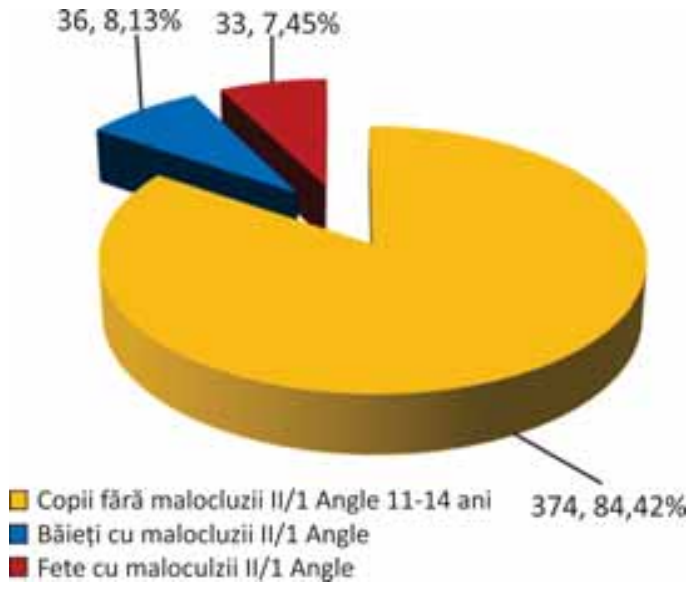

GRAFIC 4. Copii cu malocluzii clasa II/1 Angle din mediul urban la grupa de vârstă 11-14 ani

Dintre aceştia, am găsit 30 de copii $(6,77 \%)$ [11 (2,48\%) băieți şi 19 (4,29\%) fete] cu respirație orală care a determinat apariția malocluziei clasa II/1 Angle.

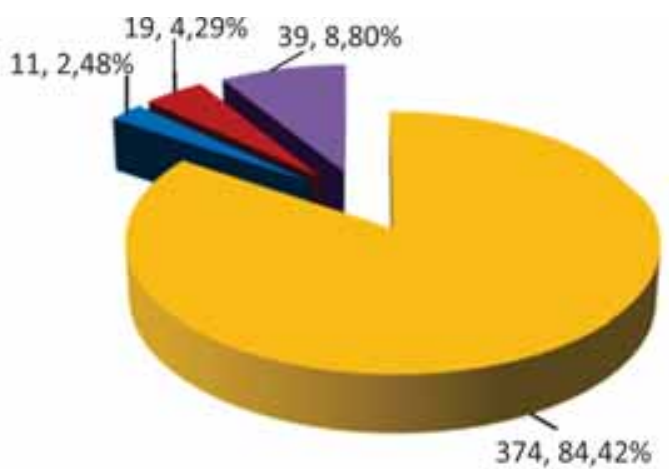

$\square$ Copii fără malocluzii II/1 Angle 11-14 ani

— Băieți cu malocluzii II/1 Angle cu factor etiopatogenetic respirația orală - Fete cu malocluzii II/1 Angle cu factor etiopatogenetic respiratia orala Copii cu malocluzii II/1 Angle cu alţi factor etiopatogenetici

GRAFIC 5. Copii cu malocluzii clasa II/1 Angle determinate de respirația orală, cu vârste cuprinse între 11 şi 14 ani din mediul urban
Am observat că, la grupa de vârstă 6-10 ani, procentul copiilor cu malocluzii clasa II/1 Angle determinate de respirație orală $(7,73 \%)$ este mai mare decât la grupa de vârstâ 11-14 ani (6,77\%). La grupa de vârstă 6-10 ani, numărul fetelor cu respirație orală (18) care a condus la apariţia malocluziei clasa a II/1 Angle este mai mare decât al băieților (15). La grupa de vârstă 11-14 ani, numărul fetelor cu respirație orală (19) care a determinat apariția malocluziei clasa II/1 Angle este mai mare decât al băieților (11).

În mediul rural, am examinat 865 de copii, dintre care $309(35,7 \%)$ cu vârste cuprinse între 6 şi 10 ani şi $556(64,3 \%)$ de copii cu vârste cuprinse între 11 şi 14 ani.

În mediul rural, am identificat $122(14,10 \%)$ de copii cu malocluzii clasa II/1 Angle, dintre care 56 $(6,47 \%)$ de copii cu malocluzii clasa II/1 Angle care au avut ca factor etiopatogenic respirația orală.

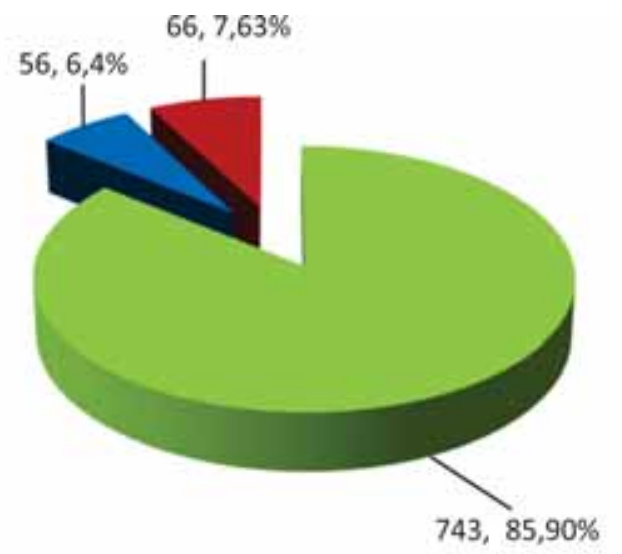

Copii fără malocluzii II/1 Angle mediul rural

Copii cu malocluzii II/1 Angle cu factor etiopatogenetic respirația orală Copii cu malocluzii II/1 Angle cu alți factori etiopatogenetici

GRAFIC 6. Copii cu malocluzii clasa II/1 Angle din mediul rural

La grupa de vârstă 6-10 ani 31 (10,03\%) de copii $[17(5,50 \%)$ băieți şi $14(4,53 \%)$ fete] au prezentat malocluzii clasa II/1 Angle.

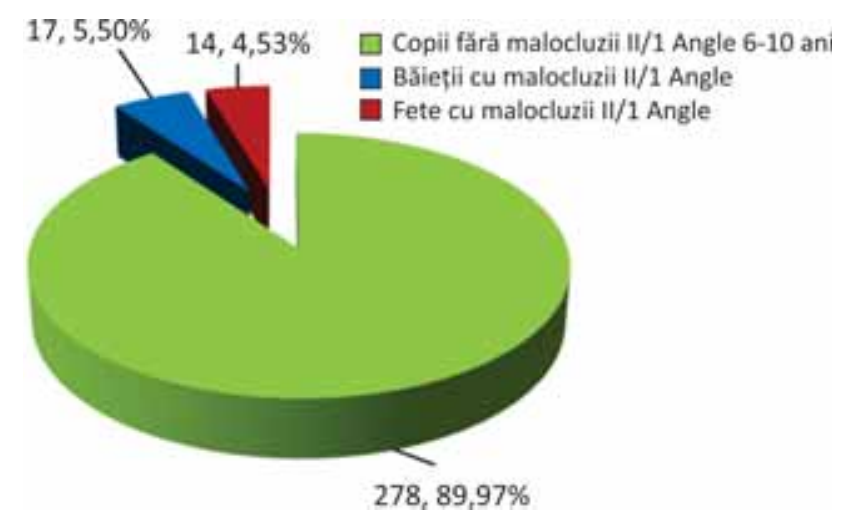

GRAFIC 7. Copii cu malocluzii clasa II/1 Angle din mediul rural la grupa de vârstă 6-10 ani 
Respirația orală ca factor etiopatogenic în producerea acestei malocluzii a fost identificată la 24 copii $(7,76 \%)$ [12 fete $(3,88 \%)$ şi $12(3,88 \%)$ băieți].

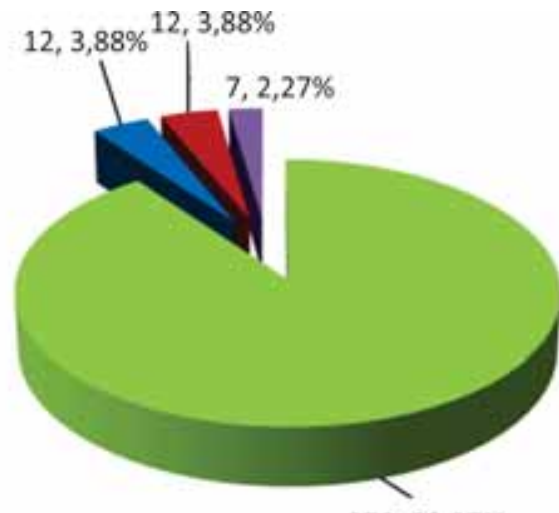

$278,89,97 \%$

口 Copii fără malocluzii II/A Angle 6-10 ani

- Bảieț cu malocluzii 11// Angle cu factor etiopatogenetic respirația orală - Fete cu maloculzii II/I Angle cu factor etiopatogenetic respirația orală - Copii cu malocluzii II// Angle cu alți factori etiopatogenetici

GRAFIC 8. Copii cu malocluzii clasa II/1 Angle determinate de respirația orală, cu vârste cuprinse între 6 şi 10 ani din mediul rural

La grupa de vârstă 11-14 ani, din cei 556 de copii examinați, $66(11,87 \%)$ [31 (5,58\%) băieți şi 35 $(6,29 \%)$ fete au prezentat malocluzii clasa II/1 Angle.

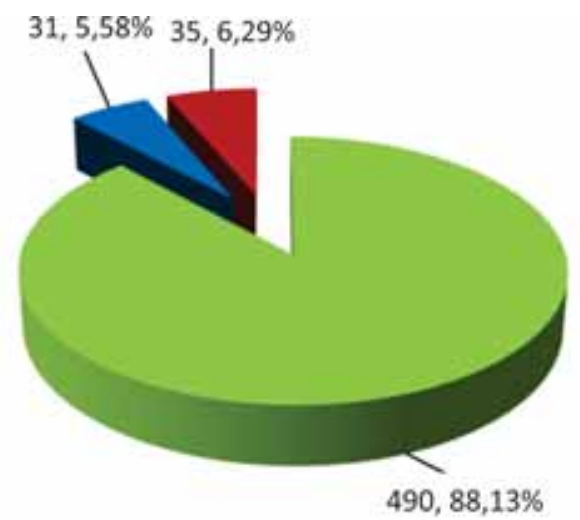

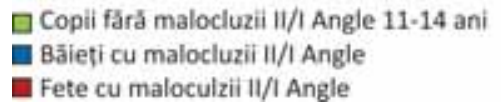

GRAFIC 9. Copii cu malocluzii clasa II/1 Angle din mediul rural la grupa de vârstă 11-14 ani

Dintre aceştia, au fost găsiţi 32 copii $(5,75 \%)$ [17 (3,06\%) băieți şi 15 (2,70\%) fete] cu respirație orală care a determinat apariția malocluziei clasa II/1 Angle.

Am observat că şi în mediul rural la grupa de vârstă 6-10 ani procentul copiilor cu malocluzii clasa II/1 Angle determinate de respirație orală $(7,76 \%)$ este mai mare decât cel de la grupa de vârstă $11-14$ ani $(5,75 \%)$.

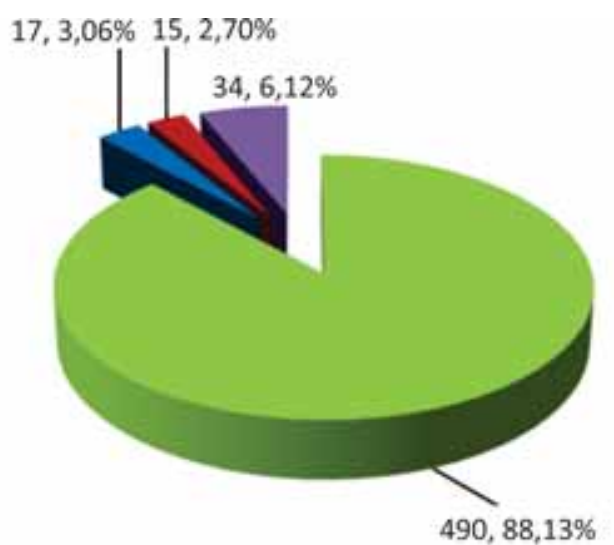

$\square$ Copii fără malocluzii II// Angle 11-14 ani

a Băieți cu malocluzii II/I Angle cu factor etiopatogenetic respirația orală - Fete cu malocluzii II/I Angle cu factor etiopatogenetic respirația orala a Copii cu malociuzii II// Angle cu alți factori etiopatogenetici

GRAFIC 10. Copii cu malocluzii clasa II/1 Angle determinate de respirația orală, cu vârste cuprinse între 11 şi 14 ani din mediul rural

La grupa de vârstă 6-10 ani, numărul băieților (12) cu respirație orală şi malocluzie clasa II/1 Angle este egal cu cel al fetelor (12). La grupa de vârstă 11-14 ani, numărul băieților cu respirație orală şi malocluzie clasa II/1 Angle (17) este mai mare decât al fetelor (15).

Putem concluziona că în mediul urban $(7,24 \%)$ prevalența respirației orale în etiologia malocluziei clasa II/1 Angle este mai mare decât în mediul rural $(6,47 \%)$.

Boboc Gh. (2) observă existența cercului vicios dintre respirația orală şi tulburările scheletale care se potențează reciproc.

Grippaudo C. et al. (3) au fãcut studii statistice şi au evidențiat corelația dintre respirația orală şi malocluziile de clasa a II-a Angle.

De asemenea, Rossi et al. (6) au subliniat în studiul lor influența respirației orale asupra tulburărilor de dezvoltare scheletală.

Zicari et al. (1) au atras în cercetarea lor atenția asupra intercorelației dintre respirația orală şi modificările scheletale, recomandând un tratament ortodontic cu colaborarea medicilor: alergolog, pediatru şi ORL-ist.

Pradeep Vishnoi et al. (7) au găsit o prevalență de $10,6 \%$ a respirației orale în cadrul obiceiurilor vicioase practicate de copii cu vârste cuprinse între 7 şi 16 ani.

Shetty et al. (8) menționează o prevalență de 4,1\% a respirației orale observând copii cu vârste cuprinse între 3 şi 16 ani. Autorii evidențiază o co- 
relație semnificativă între malocluzia clasa II/1 Angle şi respiraţia orală

Studiul nostru se încadrează în observațiile menţionate în literatura de specialitate cu privire la interdependența dintre respirația orală şi malocluzia de clasa II/1 Angle.

\section{CONCLUZII}

Este de remarcat prevalența respirației orale în etiopatogenia malocluziei clasa II/1 Angle. Studiul

\section{BIBLIOGRAFIE}

1. Zicari A.M., Albani F., Ntrekou P., Rugiano A., Duse M., Mattei A., Marzo G. Oral breathing and dental malocclusions, European Paediatric Dentistry, Vol 10/2-2009, pg. 59-64;

2. Boboc Gh., Anomaliile dento-maxilare, Ed. Medicală, Bucureşti, 1971, pg. 81-82;

3. Grippaudo C., Paolantonio E.G., Antonini G., Saulle R., La Tore G., Deli R. Association between oral habits, mouth breathing and malocclusion, Acta Otorhinolarynglo. Ital, 2016, 36(5): 386-394;

4. Fratu Aurel V. Ortodonţie. Diagnostic. Clinică. Tratament., Ed. Vasiliana, laşi, 2002, pg. 123 -125;

5. Cuţui M., Neştianu V., Tărâţă M. Electromiografia computerizată în patologia ortodontică, Ed. Aius, Craiova, 1997, pg.91-92, 95-96. nostru atrage atenția asupra faptului că permanentizarea respirației orale la copii determină tulburări de dezvoltare cranio-facială cu instalarea malocluziei de clasa II/1 Angle. Aşadar, este necesară depistarea precoce a respirației orale în vederea instituirii unui tratament ortodontic adecvat.

Notă: Toți autorii au participat în mod egal la realizarea acestui articol.

\section{Conflict of interest: none declared Financial support: none declared}

6. Pradeep Vishnoi, Prabhuraj Jambalyal, Tarulatha Revanappa Shyagali, Deepak P. Bhayya, Rutvik Trivedi, Jyoti Jingar. Age-wise and Gender-wise Prevalence of Oral Habits in 7-16 year-old School Children of Mewar Ethnicity, India, Indian Journals of Dental Sciences Vol. 9, Issue 3, Jul-Sept, 2017, pg.-184-187;

7. Rosa Carrieri Rossi, Nelson Jose Rossi Nelson Jose Carrieri Rossi, Helio Kiitiro Yamashita, Shirley Shizue Nagata Pignatari. Dentofacial Characteristics of oral Breathers in different ages: a retrospective case-control study, Progress in Orthodontics, 15 Jul. 2015, 16-23;

8. Shetty S.R., Munshi A.K. Oral Habits in children -a prevalence study, Indian Journals Soc. Pedod. Prev. Dent., Jun. 16 (2): 61-6, 1998 